\title{
El estrangulador poeta
}

\author{
GEORGES TYRAS
}

Mire usted, yo soy un poeta.

Manuel Vázquez Montalbán

Muere un poeta y la creación se siente

herida y moribunda en las entrañas.

Miguel Hernández

Fue durante su reclusión como preso político en la cárcel de Lérida, entre 1962 y 1963, cuando Manuel Vázquez Montalbán compuso su primer poemario: Una educación sentimental que, por motivos circunstanciales, sólo se publicará en $1967^{1}$. El libro era lo bastante novedoso como para que su autor figurase entre los nueve poetas a los que la famosa antología de Josep-María Castellet canonizó en 1970 como novísimos, portavoces de una notable renovación estética ${ }^{2}$.

Propongo en esta ponencia añadir a los criterios de innovación el de un vínculo orgánico que se establece entre la obra en prosa y la obra en verso, vínculo que evocaré en términos generales primero y centrándome en la novela El estrangulador luego ${ }^{3}$.

Inaugurada con Una educación sentimental, la obra poética del escritor se compone de:

$-$

1 “Una educación sentimental, publicado en 1967, estuvo escrito desde 1963 y sólo por motivos de represión administrativa y de poquedad económica del heroico editor José Batlló, no pudo editarse hasta cuatro años después", explica el escritor en la posdata a la edición de Memoria y deseo. Obra poética (1963-1983). Barcelona : Seix Barral, 1986, pág. 277). La publicación fue posible gracias a la generosa amistad de Pere Gimferrer, quien donó parte del Premio Nacional de Literatura concedido por Arde el mar (1966).

${ }^{2}$ Nueve novísimos poetas españoles reúne, categorizándolos en Los Seniors y La Coqueluche, los nombres de Manuel Vázquez Montalbán, Antonio Martínez Sarrión y José María Álvarez por una parte, y de Félix de Azúa, Pedro Gimferrer, Ana María Moix, Vicente Molina Foix, Guillermo Carnero y Leopoldo María Panero por otra parte (Barcelona: Barral, 1970).

${ }^{3}$ Manuel Vázquez Montalbán, El estrangulador. Barcelona: Mondadori, 1994 (Literatura Mondadori, 20). La novela se mereció el Premio Nacional de la Crítica 1994. 
- 1967 [1963] : Una educación sentimental

- 1969: Movimientos sin éxito (Premio Vizcaya de Poesía)

- 1973: Coplas a la muerte de mi tía Daniela

- 1973: A la sombra de las muchachas sin flor (Poemas del amor y del terror)

- 1982: Praga

- 1986 [1996 y 2000]: Memoria y deseo. Obra poética (1963$1990)^{4}$

- 1990: Pero el viajero que huye

- 1997: Ciudad

La producción lírica de Manuel Vázquez Montalbán no es prolífica pero se inscribe con constancia en el curso del tiempo y de la escritura, de manera paralela a las sucesivas mutaciones de la obra novelística. Cada poemario es un hito en una producción dedicada a la tensión entre memoria y deseo, o entre ser íntimo y sujeto socio-histórico. Recorren este conjunto unas obsesiones que vertebran el universo literario del escritor: la inscripción del individuo en una historia y una memoria colectivas, la confiscación de los ideales de la modernidad por poderes fácticos de toda especie, la búsqueda de un imposible Sur metafórico y, consecuentemente, en términos de recepción, la conversión del lector en un investigador extra-textual, a quien le corresponde descifrar el enigma de una historia que lo condena a vivir en sus márgenes ${ }^{5}$.

Los versos libres, escalonados y no rimados, como una proclama de libertad de escritura, aparecen teñidos de la ironía, cuando no el sarcasmo, que caracteriza también la escritura prosaica. A nivel formal, la for-

\footnotetext{
${ }^{4}$ Este libro-balance tuvo una primera edición en 1986. La de 1996 se tiene que considerar como la versión definitiva, en la medida en que, publicada después de Pero el viajero que huye, cierra el ciclo dedicado a las dos grandes tensiones, epónimas del poemario, que estructuran el universo mental y escritural de Vázquez Montalbán. Ciudad inaugura una fase más esencialista, a la par que más introspectiva.

${ }^{5}$ Véase el estudio que propone Manuel Rico en Memoria, deseo y compasión. Una aproximación a la poesía de Manuel Vázquez Montalbán. Barcelona: Mondadori, 2001. Del mismo autor, se puede consultar la edición de Una educación sentimental y Praga. Madrid: Cátedra, 2001 (Letras hispánicas, 512). Imprescindible queda la lectura magistral de las cinco palabras constitutivas de un verso de Praga - "vida historia rosa tanque herida" - propuesta por Josep-María Castellet en su prólogo a la primera edición de Memoria y deseo. Obra poética (1963-1983). Barcelona: Seix Barral, 1986.
} 
ma poética se ofrece desde el principio como un constituyente medular de la creación montalbaniana, hasta el punto de marcar su obra narrativa por su presencia misma, notable a simple lectura. A nivel temático, no se da en el escritor barcelonés solución de continuidad alguna entre prosa y poesía. Las modalidades de esta contaminación recíproca se pueden definir en términos de transtextualidad: desde la mera alusión hasta la utilización de un texto poético como motor narrativo (Tatuaje), pasando por todos los avatares de la segunda mano, para utilizar la afortunada metáfora de Antoine Compagnon ${ }^{6}$.

Los textos de la experimentación subnormal, en los años sesenta y primeros setenta, muestran que Manuel Vázquez Montalbán cultiva lo heterogéneo, desde la voluntad ética y estética de (con)fundir las modalidades de escritura tradicionales. A nivel ético, el escritor se niega a considerar que puedan existir unas formas de expresión nobles, patrimonio de una élite social y/o cultural (la poesía, el ensayo) y otras devaluadas, reservadas para el consumo plebeyo (la canción popular, la paraliteratura). Su labor, tanto o más que la de un creador, es la de un recreador, que tiende a conferir a cada modalidad expresiva la misma dignidad literaria. A nivel estético, se sitúa consecuentemente en la óptica contemporánea, que algunos llaman posmoderna, y que consiste en dejar de considerar como operatorias las distinciones que enseña la tipología tradicional: la novela, el artículo de prensa, el poema, el sainete teatral, el cuento, la canción popular, el ensayo, la receta de cocina se compenetran y se contaminan.

A este mecanismo de erosión de las fronteras genéricas remite la fecundación semántica de los textos novelescos por textos poéticos. Los ejemplos son múltiples a lo largo de la obra. La figura del protagonista de Autobiografía del general Franco (1992) se ilumina en contraposición con las siluetas que pueblan poemas como "Plaza de Oriente" o "Su piel anciana bien cuidada", incluidos veinte años antes en la sección de los "Poemas del terror" de A la sombra de las muchachas sin flor. Idéntico comentario se merece el fenómeno de los textos migrantes, según el cual piezas escritas específicamente para un texto narrativo se ven recogidas en un poemario, provocando que se oigan en él, no sólo sus propias notas armónicas, sino las de la novela de la que provienen originalmente. Tal es el caso para el "Poema de Dardé", escrito para Recordando a

${ }^{6}$ Antoine Compagnon, La seconde main ou le travail de la citation. Paris: Seuil, 1979. 
Dardé (1969), y para el "Poema de Lady Bird" aparecido en Yo maté a Kennedy (1972). Ambos textos fueron incluidos en la versión ampliada de Una educación sentimental, que se editó en el libro Memoria y deseo en 1986. Ambos incitan a leer retrospectivamente las novelas como modalidades de educación sentimental. El efecto también se puede invertir y muchos poemas se aclaran a la lectura del texto en prosa que lo acoge. Ocurre por ejemplo para "Correo sentimental. Respuesta a Enide", composición difícil incluida en Movimientos sin éxito y que se aclara si se coteja con la novela Erec y Enide, de publicación mucho más reciente ${ }^{7}$; también para "Gauguin", poema de Una educación sentimental que sólo cobra su pleno significado a la luz proyectada por un ensayo consagrado al pintor, Gauguin : la larga huida ${ }^{8}$.

Ejemplo paradigmático, El estrangulador (1994) es una novela literalmente saturada por la escritura poética. El lector se halla en compañía de algunos de los poetas predilectos del escritor barcelonés (desde el autor de letras de canciones Rafael de León hasta Eliot, pasando por Baudelaire y Cocteau), pero también se encuentra con citas seudoapócrifas, que constituyen una de las marcas de fábrica de la creación montalbaniana. El escritor practica una forma lúdica de la intertextualidad, restringida a su propia escritura. Y el hecho de que el lector sea capaz de identificar las manifestaciones del procedimiento contribuye al desciframiento del sentido. Es productivo distinguir, por ejemplo, en cierta alusión a la seducción de "la muchacha dorada", la sombra proyectada por una estrofa de "Las huidas", un poema del libro A la sombra de las muchachas sin flor $^{9}$, o, en un grupo de versos sobre la tensión entre olvido y deseo (Estrangulador 106), una cita de "Rosa de dos vientos", poema de Pero el viajero que huye, o también, en lo que el protagonista

\footnotetext{
${ }^{7}$ Barcelona: Areté, 2002 (o sea 35 años después del poemario). Esta iluminación retrospectiva de los textos, favorecida por las mutaciones de las plasmaciones formales, pone de relieve un rasgo pertinente de la escritura montalbaniana : la existencia de problemáticas de las que el escritor es portador de manera endémica, y que surgen episódicamente con motivo de tal o cual provocación circunstancial, en una relación que se emparenta con una especie de hipertextualidad latente.

${ }^{8}$ En Geometría y compasión, Barcelona, Mondadori, 2003, págs. 23-51. Este texto es de 1991, fecha de su publicación en Francia (Paris: Flohic, 1991 (Musées secrets, 6) pero no tuvo edición española hasta la referida.

${ }^{9}$ De hecho, este poema también pertenecía a Una educación sentimental; su recuperación en el poemario de 1973 contribuye a darle toda su significación.
} 
de la novela presenta como su tango preferido, pág. 124 sq., el eco burlesco de "Homage to tango" incluido en el Manifiesto subnormal (1970).

\section{La novela El estrangulador (1994)}

A pesar de estos horizontes familiares, El estrangulador es una novela difícil y exigente, que expresa, mediante las inmóviles peripecias del encierro clínico, une actitud de rebelión frente a todas las formas de opresión que permiten sojuzgar al individuo. Protagonizado por un inolvidable personaje de fontanero asesino en serie, es un texto subversivo que aboga por la construcción de una ciudad que pudiera ser "ese lugar del que no se quiera regresar" $" 10$.

Esta postura rebelde se erige al filo de los capítulos y en conformidad con la dualidad esquizofrénica del protagonista, en un esquema estructurador que determina no sólo la distribución binaria de las peripecias, sino la naturaleza dual de varios recursos compositivos de la novela. Presentaré rápidamente las figuras más productivas de la dualidad: el dualismo morfológico de la novela, el dualismo genérico novela/ensayo, y el dualismo actancial escritor/personaje.

Dualismo morfológico: dos partes

La novela consta de dos partes, enunciadas por quien se presenta en la primera parte como el verdadero estrangulador de Boston, Albert DeSalvo, y confiesa en la segunda ser Albert Cerrato, un autista mitómano. La onomástica - un solo nombre, dos apellidos- juega con la dialéctica identidad vs alteridad. Este juego tiene un eco literario en algunos indicios paratextuales: el título de la primera parte, Retrato del estrangulador adolescente, remite al Portrait of the artist as a young man (1916), de James Joyce, mientras que el de la segunda, Retrato del estrangulador seriamente enfermo remeda el Diario del artista seriamente enfermo (1974) de Jaime Gil de Biedma. Los dos textos de referencia abogan por la creación artística como vía de escape al determinismo o al encierro familiar y social.

\footnotetext{
$-$

${ }^{10} \mathrm{El}$ artesano fontanero recluso es, en los términos acertados de Miguel Riera, un esteta : "Un artista que convierte el asesinato en una instalación propia del arte postconceptual. Un asesino posmoderno. El sarcasmo de Vázquez Montalbán abunda en detalles de ese tipo, poniendo en cuestión reiteradamente todas las vertientes de la cultura posmoderna; una cultura que permite la instalación como forma de comunicación artística, y en la que también pueden instalarse asesinos y retretes" (Riera 1994)
} 
Esta dualidad estructural refleja la configuración mental bipartita del protagonista, e informa el relato en cualquiera de sus implicaciones: ¿Estamos en Boston o en Barcelona? ¿quién protagoniza la novela, DeSalvo o Cerrato? Es un psicópata o una víctima? ¿Un impostor o un soñador? ¿Puede el hombre ser otra cosa para el hombre que un lobo o un loco? ¿Puede el lenguaje ser algo más que la sombra de la realidad? Etc.

En el terreno abonado de dichos interrogantes florece una serie de alternativas que estructuran la confesión del protagonista : ficción $v s$ realidad, historia vs psicoanálisis, Marat vs Sade, geometría vs compasión, memoria vs deseo. Y la novela cobra entonces la dimensión de una parábola, sobre el individualismo, el aislamiento, la pérdida de valores, la mutación de las sociedades contemporáneas, el descrédito de los grandes relatos explicativos, el sueño o el recuerdo como refugios.

Dualismo genérico: novela y ensayo

La intriga de la novela es clara: el personaje del estrangulador somete al lector a una letanía de ejecuciones truculentas, convirtiendo el relato en un avatar de ficción policiaca; el serial killer retratado en la primera parte se metamorfosea en la segunda parte en un autista cuya confesión pone en tela de juicio sus propias hazañas asesinas.

Novela a priori, El estrangulador afirma paralelamente su densidad erudita: casi todos los micro-relatos que generan cada asesinato y su desmentido sirven de soporte a una especie de eflorescencia digresiva, reivindicada por el protagonista: "Mis digresiones cultas siempre han puesto nerviosos a mis interlocutores y ahora suelo extremarlas ante los psiquiatras penitenciarios [...]" (Estrangulador: 15). La digresión opera tanto a nivel de la diégesis, en la que tiene valor de medio de defensa del protagonista frente al poder médico, como a nivel del relato, en el que y contra el que se ofrece como modalidad de escritura alternativa. La beligerancia se resuelve a favor de la digresión, que cobra más importancia que el trozo narrativo que la motiva y permite que el estrangulador emita virulentas diatribas contra el estado del mundo contemporáneo. Así se cumple la verdadera función de un texto que resulta ser tanto o más un ensayo político que una novela.

Un comentario análogo se merece la relación que se establece entre ambos textos, relato y digresión, y las notas a pie de página. El texto está en efecto plagado de notas, con las que recalca su duplicidad genérica, en conformidad con la voluntad de DeSalvo, quien afirma a la vez el carác- 
ter autógrafo del texto (diario íntimo, dietario, confesión) y su hibridez constitutiva, que le permite abrir amplios horizontes dialógicos y críticos.

Un ejemplo entre varios: en el capítulo 6 de la primera parte DeSalvo se lanza en una digresión que tiene por objeto el simbolismo de la cerbatana en la mitología maya. Pero motiva una nota de más alcance que evoca los estragos provocados por los sistemas de pensamiento cristianocapitalista o cristiano-comunista sobre las civilizaciones indígenas, y pone de relieve el papel de la rebelión de Chiapas, en 1994, en el proceso de reconocimiento de los derechos de los indios.

Se entiende perfectamente, entonces, que el protagonista ponga en la picota a los psiquiatras que se obstinan en reducir a un caso de esquizofrenia lo que es un caso de crisis histórica del sujeto: "me reducen a la condición de asesino de mí mismo, atraído por la digresión de matar a los otros" (Estrangulador 43). La fórmula es una de las claves del texto: induce a invertir los términos de la relación binaria y a considerar el relato de los asesinatos como una digresión con respecto a la reflexión sociológica o socio-histórica que lo acompaña. De manera homóloga a la poesía, el discurso ensayístico es un espacio de libertad.

Dualismo actancial: el estrangulador y el escritor

De acuerdo con el propósito de la novela, el escenario de los crímenes del estrangulador, Boston, es una metáfora:

[...] Boston es el mundo, este mundo actual que es un mundo austrohúngaro, un imperio caído y sin aparente finalidad, percibido por Cerrato desde la descomposición del yo burgués, la misma descomposición que en Klimt fecundó creatividad y en Cerrato locura y maldad imaginaria (Estrangulador 258).

Es llamativa por otra parte la abundancia de los comentarios que convierten Boston en la proyección, o la imagen fantasmada de Barcelona, una ciudad absolutamente central en la creación montalbaniana ${ }^{11}$; valga como ejemplo esta alusión indignada a una de las vitrinas de la posmodernidad:

[...] la reforma urbana de Boston con motivo de los Juegos Olímpicos había significado el derrumbe del barrio de las putas ostensibles y pobres (Estrangulador 193).

$-$

${ }^{11} \mathrm{Cf}$. "El barcelonismo se me supone [...] porque toda mi literatura está hecha desde la barcelonía del espacio que comparto y del tiempo que he vivido.” (Barcelonas 1987: 7) 
O también la evocación, más intimista, de:

[...] aquella compañera de juegos de los anocheceres en la plaza de fuente con estatua de santa, martirizada por el procedimiento de cortarle las tetas (Estrangulador 63 sq.).

Transparente alusión a la plaza del Padró, dominada por la estatua de Santa Eulalia, en el corazón del barrio del Raval donde transcurrió la infancia del escritor. Y valga para terminar la divertida lista de especialidades culinarias de Boston que culmina con "el indispensable pan con tomate, sin el cual los bostonianos no sabríamos comer" (Estrangulador 173).

Se recalca así irónicamente una dimensión personal: la mayor parte de las notaciones que superponen Barcelona a Boston atribuyen al personaje del estrangulador muchos de los rasgos que se suelen llamar biografemas, es decir detalles sacados de la biografía del autor. Se pueden identificar, entre otros: las precisiones socio-históricas sobre el barrio del Padró, barrio de vencidos de la guerra civil en los años 40 y de inmigrantes en los años 50, del que Manuel Vázquez Montalbán dice en otro texto que "le sobraba a la burguesía", y cuyos habitantes apenas se atreven a salvar la frontera (Estrangulador 37, 82, 99); la repetida definición del protagonista como un niño de balcones, desde donde contempla el espectáculo de la calle (Estrangulador 31, 34, 37, 58, 64); las precisiones sobre la instalación de la familia en el barrio medio siglo antes (Estrangulador 34), el oficio de modista de la madre (Estrangulador 34), la posesión de un coche de lujo de marca inglesa ${ }^{12}$.

El conjunto así constituido puede ponerse en relación con una de las facetas de la intertextualidad abundante que impregna el texto: las frecuentes referencias al universo literario carvalhiano. El lector experimenta un placer de iniciado al entender la alusión al personaje del adolescente sensible, o de la muchacha dorada, a resituar el pseudo proverbio latín "Navegar es necesario, vivir no lo es", o a identificar la novela donde ya se produjo un asesinato con botella de champán como el que comete el estrangulador. Numerosas son las alusiones que contribuyen a convertir al estrangulador en un personaje carvalhiano, cuando no en una especie

\footnotetext{
-

${ }^{12}$ Es de notar que con motivo de dicho coche el escritor se designa de forma explícita y sarcástica: "[...] un Jaguar Sovereign propiedad de uno de los líderes intelectuales de la fracción de ecomarxistas catastrofistas que cobra cinco mil dólares por cada conferencia contra la irracionalidad del sistema capitalista e incluso siete mil si la entidad bancaria que le contrata es de las más poderosas (Estrangulador 233).”
} 
de Carvalho que estaría llevando sus propias características a sus últimas consecuencias $^{13}$.

De manera más fundamental, hace falta interrogarse sobre el significado de la resurgencia en la novela de preocupaciones atribuidas al estrangulador cuando se sabe que son fundamentalmente las del escritor. Por ejemplo esta confesión de Cerrato:

Me gustaría, Alma, regresar a nuestro ámbito para matar definitivamente los recuerdos y recobrar la vida, detrás incluso de los rostros que se interferían como un paisaje humano demasiado convencional. Del fondo de un océano horroroso, cruelmente oscuro, suben las submarinas voces de los ahogados, de los muertos que sólo yo recuerdo [...] (Estrangulador 199 sq.)

Declaración espléndida, porque permite ver cómo los lenguajes poéticos y prosaicos se iluminan recíprocamente. La cita vincula de manera compleja varios textos. Por una parte el olvido de los seres desaparecidos se toma de un poema de Salvador Espriu, citado como epígrafe de Una educación sentimental: "Pero ara és la nit / i he quedat solitari / a la casa dels morts / que nomès jo recordo." Es una de las obsesiones primordiales del escritor y vuelve como un estribillo en su obra. Por otra parte, la expresión del vínculo entre recuerdos y vida, variante de la tensión entre memoria y deseo, es una prosificación del principio de un poema titulado "La ciudad", que es una pieza esencial de la obra. En efecto, articula las dos partes de la novela (Estrangulador 146-149), y resulta ser, con algunas leves modificaciones, uno de los componentes de Ciudad, el último poemario de Manuel Vázquez Montalbán ${ }^{14}$. O sea que cuando DeSalvo reivindica "mi poema, inédito, La ciudad" (Estrangulador 146), dice media verdad y media mentira: el poemario Ciudad sólo quedará inédito has-

\footnotetext{
${ }^{13}$ Un Carvalho asesino en serie, de alguna manera... Esta inversión de la relación entre verdugo y víctima, que puede interpretarse como un avatar de la subversión, ocurre en $E l$ hombre de mi vida, publicado en 2000.

${ }^{14}$ El libro tiene estatuto específico, en la medida en que con él empezaba, por aquella fecha, un nuevo ciclo poético, llamado a concretar las orientaciones hacia una obra más reflexiva y esencialista que aportaba el poemario anterior, de 1990, Pero el viajero que huye. Como lo subraya una nota del autor, y lo confirman las sucesivas ediciones de Poesía completa, así se cerraba un ciclo de escritura dedicado a la metabolización de los materiales de la experiencia, ciclo colocado bajo el signo de Memoria y deseo. Sobre la obra poética del escritor, véase Manuel Rico, Memoria, deseo y compasión. Un aproximación a la poesía de Manuel Vázquez Montalbán. Barcelona, Mondadori, 2001.
} 
ta 1997, pero no es de DeSalvo, sino de Vázquez Montalbán, y asistimos así a una modalidad de delegación de la voz del autor a su personaje.

\section{De "La ciudad" a Ciudad}

Ciudad es un poema unitario, compuesto de siete piezas numeradas de uno a siete, como los siete días de la semana o las siete etapas necesarias para completar la reconstitución de una ciudad de la que no se percibe de inmediato la naturaleza última. El recorrido conforma una ciudad más bien mental, ya desprovista de los referentes explícitos que caracterizaban la etapa anterior (Praga). La construcción también es la del propio texto Ciudad, acabado en la séptima estación, punto de llegada de una trayectoria de doble dimensión: existencial y literaria. El conjunto se presenta como la crónica poetizada de una vida, itinerario vital más bien desolador que pasa por etapas lógicas o tópicas (como la fascinación inaugural, el obligado acatamiento a las realidades generadas por el poder, o la pérdida de la inocencia y la esperanza) y lleva a un naufragio final que simboliza la destrucción por los "bárbaros" de todo asomo de utopía. El poemario Ciudad dibuja un trayecto que termina en un imaginario domingo metafórico en el que el poeta contempla impotente lo que queda del paisaje al que ha regresado:

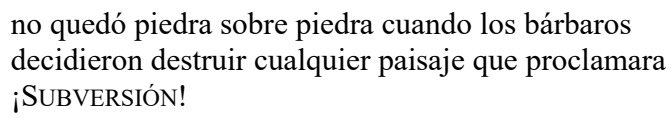

Este sentimiento de un implacable fracaso no es absolutamente nuevo en Manuel Vázquez Montalbán, ni nace ex nihilo cuando la publicación del poemario Ciudad. La etapa o derrota final, ya la expresa el poema originario, el de la novela, titulado "La ciudad". De hecho, el propio autor confiesa en un "A manera de epílogo" a la obra que la idea de la misma nació unos treinta años antes:

[...] al final de la década de los sesenta, José Agustín Goytisolo me encargó un poema glosa de la metafísica arquitectónica de Ricardo Bofill, en aquel momento empeñado en hacer realidad La ciudad en el espacio. Yo escribí un poema sobre una ciudad y al acabarlo me dí cuenta de que estaba dedicado a la ciudad de la Memoria, 
prueba evidente de que ya había cumplido treinta años, la edad en que termina la inocencia y se construye la memoria como una novela interiorizada (Ciudad 51) ${ }^{15}$.

Entre otras informaciones preciosas, este breve texto atestigua la existencia de un poema primigenio, su papel germinal en la elaboración del poemario Ciudad y su importancia en la economía de la novela El estrangulador. Desde el punto de vista estructural, es obvia la importancia del poema como núcleo de la novela, en la que se cita varias veces:

- un fragmento de 17 versos en el cap. $1 / 11,72$

- íntegro (92 versos) en el cap. $1 / 24,146-149$

- glosado en el informe psiquiátrico final sobre Cerrato, cap. 2/15, $257 \mathrm{sq}$.

- insertado en la carta que Cerrato dirige a Alma, cap. 2/8, 199

- aflora en la prosa confesional del mismo, cap. 2/12, $223 \mathrm{sq}$

- satura el final de la novela, cuyo texto de hecho invade por completo, cap. 14, 267

"La ciudad" elabora un imaginario de inspiración eliotiana, con "un montón de imágenes rotas sobre el que cae el sol" (Movimientos sin éxito). La ciudad que evoca el poema, privilegiando la compasión en detrimento de la geometría, es, de la misma manera que el autismo, mucho más que un refugio contra lo exterior: como lo apunta el estrangulador, "la poesía es una peligrosa arma de futuro, ya que sólo puede apostar por futuros perfectos y los futuros son, por naturaleza, imperfectos" (Estrangulador 188).

"La ciudad" permite conectar la novela con el último poema del ciclo anterior, "Definitivamente nada quedó de abril", de Pero el viajero que huye, que expresa la pérdida de los sueños emancipadores de la juventud y la derrota de los ideales modernos de los antepasados. "La ciudad" expresa una convicción fundamental del autor: al final de una existencia de sueños y renuncias, de deseos insatisfechos et de combates fracasa-

\footnotetext{
${ }^{15}$ Prosigue el autor: "Muchos años después, este poema fue el referente obsesivo de mi novela El Estrangulador y el convocante recurrente de este libro, Ciudad, que versa sobre las ciudades del cuerpo, del alma, de la memoria personal, terrestre, la memoria original de la materia en el tiempo, de la ciudad de la Historia, sin que dejara de sonar nunca una canción de Glenn Miller Canta el petirrojo en diciembre... que alguna vez escuché de niño en una ciudad donde habitan muertos que sólo yo recuerdo y que ya aparecía en mis poemas primeros de Una educación sentimental como la melodía que acompañó algún instante desvelador. Mi Rosebud.”
} 
dos, después del ineluctable movimiento de huida a los mares de todos los sures reales y metafóricos, sólo hay una ciudad a la que se puede volver, una ciudad interior, construcción verbal, último y único refugio contra el desencanto y la muerte: la ciudad de la memoria. Este es exactamente el recorrido que efectúa el protagonista de El estrangulador, entre una locura reivindicada como virus subversivo del orden burgués y una demencia resignada a no manifestarse ya sino de manera autística, mediante el refugio en el solipsismo más radical. "En el fondo, comenta Manuel Vázquez Montalbán, el único lugar donde se encuentra auténticamente liberado es cuando retorna a esa ciudad de la memoria, en la que se refugia $[\ldots]]^{\prime 16}$.

A su vez, la novela tematiza el fin de la esperanza, la victoria del escepticismo; en este conjunto, que funciona como metáfora de la barbarie del siglo XX, como exploración de las ruinas (políticas, ideológicas, existenciales) que ha dejado la caída del muro de Berlín a finales de los 80, las afinidades semánticas entre el poema y la novela se apoyan en una serie de analogías: "La ciudad" es un poema anárquico, hecho de yuxtaposiciones, asociaciones de ideas y reminiscencias intertextuales, y de léxico polisémico; El estrangulador es una novela anárquica, de argumento desestructurado, que rechaza la linealidad narrativa, y ofrece una pluralidad de significados. Ambos textos responden a una visión fragmentaria, caótica, del poco inteligible universo de fin de siglo; ambos alimentan un significado profundo que consiste en avivar el recuerdo de la ciudad destruida y mostrar que es la fuente, el núcleo primigenio, el último refugio en un mundo amenazado por la barbarie, carente ya de referentes colectivos, en un Occidente vencido por la desmemoria y el individualismo.

\section{Conclusión}

El estrangulador y su creador expresan o comparten una misma utopía : la voluntad de refugiarse en un lugar que sea un remanso de paz contra las afrentas o vejaciones que impone el mundo: "Hay viajeros que regresan a sus barrios / para matar recuerdos y recobrar la vida [...]".

\section{-}

${ }^{16}$ Georges Tyras, Geometrías de la memoria. Conversaciones con Manuel Vázquez Montalbán. Granada, Zoela, 2003, pág. 182. El escritor puntualiza, pág. 180: "La memoria es una falsificación de la realidad, pero es un lugar seguro, donde pueden cumplirse todos tus deseos. En El estrangulador, esta aparente contradicción fue la que me llevó a utilizar el poema del refugio en la ciudad de la memoria [...]." 
Este sur metafórico, este lugar del que no se quisiera regresar, es una ciudad, de naturaleza mental, la ciudad de la memoria, la ciudad de la infancia, acaso la ciudad de la placenta, único marco en el que se pueden cumplir los deseos.

Quizá a este punto que el protagonista y el escritor tienen en común se deba atribuir lo que es el primer y último guiño del libro : la curiosa dedicatoria imitada de Klimt, quien dedicaba uno de sus desnudos "A mis críticos". El estrangulador en efecto está dedicado "A mis víctimas". Las del estrangulador, por supuesto. Pero también, por las consabidas reglas de funcionamiento del paratexto, al que pertenece la dedicatoria, las del autor. Si Manuel Vázquez Montalbán reivindica el estatuto del verdugo, es que se considera también como una víctima. Cualquier relación de este tipo es perfectamente reversible, y la reclusión es el marco privilegiado de la reversibilidad.

De ahí la fuerza impactante del desenlace de la novela, que vuelve a citar el poema "La Ciudad", al final de una última y desgarradora confesión del estrangulador, quien ha encontrado el refugio más extremo: el autismo detrás de los muros carcelarios, un autismo estremecedor que sólo encuentra acogida en el único espacio donde la memoria puede sobreponerse al acoso de la razón inquisitorial del presente: el imaginario, o la literatura. Esta versión aporta a los últimos versos del poema unas leves pero muy necesarias y significativas modificaciones:

A esa ciudad, Alma, yo volvería como un indiano próspero, casado contigo, la muchacha más dorada del non plus ultra, enriquecido náufrago en el Mar de la Tranquilidad, volvería como un pájaro furtivo a picotear en los escombros de nuestra ciudad imaginaria... era tan hermosa... era tan hermosa... era tan hermosa... relatan los cronistas, que fue destruida para no quedar piedra sobre piedra cuando los bárbaros decidieron construir paisajes artificiales. Para siempre a salvo de la acechanza de la SUBVERSIÓN (Estrangulador 267) ${ }^{17}$.

\footnotetext{
${ }^{17}$ El trozo empieza de la manera siguiente: "Yo quiero una muerte que deje vivir, perdida azotea, entre el sur y la mar, entre el norte y la tierra, laberintos de hierro, lunes de guardar. Destruidas incluso las ruinas, nuestras ruinas, Alma, pediremos que construyan ciudades falsificadas donde palpar atardeceres de senos que esperarán mis manos, donde las muchachas quieran jugar a perseguir crepúsculos en los techos atravesados por el coleccionista de muertas ciudades de la memoria o la piedra... la piedra fálica e implacable del hombre acostumbrado a no hablar, siquiera a decir buenos días en la puerta de los ascensores, que nunca conducen a pisos que no existen..." (ibid.)
} 
Subversión. Palabra clave de la novela y del poema, palabra clave de la literatura y de la modernidad. Quizá la única palabra capaz de acabar con el discurso de los cautivos de toda clase, con todas las clases de discursos cautivos. El estrangulador, y Ciudad, son textos subversivos que hay que escuchar atentamente porque son himnos a la libertad.

\section{Bibliografía}

Obras de Manuel Vázquez Montalbán

Memoria y deseo. Obra poética (1963-1983). Barcelona: Seix Barral, 1986

. Barcelonas. Barcelona: Ampúries, 1987

. Gauguin. La longue fuite: Paris, Flohic éditions (Musées secrets, 6), 1991.

El estrangulador. Barcelona: Mondadori (Literatura Mondadori, 20), 1994.

. Memoria y deseo. Obra poética (1963-1990). Barcelona: Grijalbo-

Mondadori, 1996

. Ciudad. Madrid: Visor, 1997.

. El hombre de mi vida. Barcelona: Planeta, 2000.

. Erec y Enide. Barcelona: Areté, 2002.

. Geometría y compasión, Barcelona: Mondadori, 2003.

\section{Otros textos}

Castellet, José María [ed.]. Nueve novísimos poetas españoles. Barcelona: Barral, 1970.

. "Prólogo", Manuel Vázquez Montalbán. Memoria y deseo. Obra poética (1963-1983). Barcelona: Seix Barral, 1986.

Compagnon Antoine. La seconde main ou le travail de la citation. Paris: Seuil, 1979.

Rico Manuel [ed.]. Manuel Vázquez Montalbán. Una educación sentimental y Praga. Madrid: Cátedra (Letras hispánicas, 512), 2001.

. Memoria, deseo y compasión. Una aproximación a la poesía de Manuel Vázquez Montalbán. Barcelona: Mondadori, 2001.

Riera Miguel. "Geometría contra compasión”, Quimera, 129 (1994): 5256.

Tyras Georges. Geometrías de la memoria. Conversaciones con Manuel Vázquez Montalbán. Granada: Zoela, 2003. 